\title{
Serial MRI and neurobehavioural findings after mild to moderate closed head injury
}

\author{
Harvey S Levin, David H Williams, Howard M Eisenberg, Walter M High Jr, \\ Faustino C Guinto Jr
}

\begin{abstract}
Fifty patients who sustained mild to moderate closed head injury (CHI) underwent a CT scan, MRI, and neurobehavioural testing. At baseline $\mathbf{4 0}$ patients had intracranial hyperintensities detected by MRI which predominated in the frontal and temporal regions, whereas 10 patients had lesions detected by CT. Neurobehavioural data obtained during the first admission to hospital disclosed no distinctive pattern in subgroups of patients characterised by lesions confined to the frontal, temporal, or frontotemporal regions, whereas all three groups exhibited pervasive deficits in relation to normal control subjects. The size of extraparenchymal lesion was significantly related to the initial Glasgow Coma Scale score, whereas this relation was not present in parenchymal lesions. One and three month follow up MRI findings showed substantial resolution of lesion while neuropsychological data reflected impressive recovery. The follow up data disclosed a trend from pervasive deficits to more specific impairments which were inconsistently related to the site of brain lesion. These results corroborate and extend previous findings, indicating that intracranial lesions detected by MRI are present in most patients hospitalised after mild to moderate CHI. Individual differences in the relation between site of lesion and the pattern of nueropsychological findings, which persist over one to three months after mild to moderate CHI, remain unexplained.
\end{abstract}

Neurosurgery,

University of Texas

Medical Branch,

Galveston, Texas

H S Levin

D H Williams

H M Eisenberg

Neurobehavioural

Unit, Larelwood

Hospital, The

Woodlands, Texas

W M High Jr

Division of

Neuroradiology,

University of Texas

Medical Branch,

Galveston, Texas

F C Guinto Jr

Correspondence to:

Dr Levin,
Division of Neurosurgery

Division of Neurosurgery

Medical Branch, Galveston

Medical Branch, Ga
Texas 77550 , USA.

Received 6 February 1991

and in final revised form 30 June 1991.

Accepted 14 August 1991
Patients

PATIENT POPULATION

Fifty patients who met criteria for mild (40) or moderate (10) injury according to their lowest Glasgow Coma Scale (GCS) ${ }^{9}$ score were selected from consecutive admissions to the neurosurgery service for $\mathrm{CHI}$ (table 1). The criteria for mild impairment of consciousness included an initial period of unconsciousness for 20 minutes or less and no deterioration from an admission GCS score of $13-15 ;^{1011}$ whereas moderate impairment of consciousness was defined according to an admission (or lowest) GCS score 9 to 12 with no deterioration below this range. ${ }^{12}$ Although the GCS score was 7 during helicopter evacuation for one of the patients whose injury was classified as moderate, his level of consciousness rapidly improved to a GCS score of 11 in the emergency room. Patients previously admitted to hospital for head trauma or with a history of another neuropsychiatric disorder, alcoholism, or drug abuse were excluded from the study. Patients and their families consented to participate in this investigation. To evaluate neurobehavioural outcome of these head injured patients, 21 control subjects were recruited from the community by newspaper advertisements. Respondents selected were comparable to the patients in their distribution of demographic features (table 1) and had no history of neurological disease or hospitalisation for head injury or major psychiatric disorder.

\section{CT AND MRI}

The protocol specified completion of MRI within 72 hours after the first (admission) CT scan and after any operations. In cases in which MRI was delayed (for example, due to agitation) a second CT scan was obtained to provide a concurrent comparison of these neuroimaging techniques. An MRI was scheduled for moderately injured patients when they no longer needed life support equipment for clinical management (typically, on the day of transfer from the neurological intensive care unit to a hospital room).

The CT scans were obtained on a General Electric 8800 (General Electric Company, Medical Systems Division, Milwaukee, WI) in the transaxial plane without contrast enhancement. MRI was performed on a Teslacon (Technicare, Cleveland, $\mathrm{OH}$ ) system with a $0 \cdot 6$-Tesla magnetic field strength with a proton resonant frequency of $25.4 \mathrm{MHz}$. Images were acquired in contiguous $8 \mathrm{~mm}$ slices in transaxial and coronal planes with two spin-echo sequences: a repetition time (TR) of $500 \mathrm{msec}$ 
Table 1 Demographic and clinical features of patients with closed head injury and normal control subjects*

\begin{tabular}{|c|c|c|c|c|}
\hline \multirow[b]{2}{*}{ - } & \multicolumn{2}{|c|}{ Glasgow Coma Scale score } & \multirow[b]{2}{*}{$\begin{array}{l}\text { Total } \\
(n=50)\end{array}$} & \multirow[b]{2}{*}{$\begin{array}{l}\text { Controls } \\
(n=21)\end{array}$} \\
\hline & $\begin{array}{l}13-15 \\
(n=40)\end{array}$ & $\begin{array}{l}9-12 \\
(n=10)\end{array}$ & & \\
\hline Mean (SD) age (years) & $25.9(8 \cdot 0)$ & $27 \cdot 4(9 \cdot 3)$ & $26 \cdot 2(8 \cdot 2)$ & $25.8(6.4)$ \\
\hline Mean (SD) education (years) & $12 \cdot 0(2 \cdot 0)$ & $12 \cdot 3(2 \cdot 7)$ & $12 \cdot 1(2 \cdot 1)$ & $12.0(1.3)$ \\
\hline Male & & & & \\
\hline Female & 13 & 3 & 16 & 8 \\
\hline \multicolumn{5}{|l|}{ Cause of injury } \\
\hline MVA & 20 & 8 & 28 & \\
\hline Assault & 6 & 1 & 7 & \\
\hline Bicycle & 2 & 0 & 2 & \\
\hline Sports & 1 & 0 & 1 & \\
\hline Fall & 2 & 0 & 2 & \\
\hline Other & 9 & 1 & 10 & \\
\hline Mean (SD) GCS score & $14 \cdot 4(0 \cdot 66)$ & $9 \cdot 7(0 \cdot 82)$ & $13.4(2 \cdot 0)$ & \\
\hline \multicolumn{5}{|l|}{ Mean (SD) time to obey commands } \\
\hline Mean (SD) duration of PTA (days) & $\begin{array}{l}0.009(0.01) \\
1.85(3 \cdot 21)\end{array}$ & $\begin{array}{l}1.33(1 \cdot 25) \\
9 \cdot 44(8 \cdot 16)\end{array}$ & $\begin{array}{l}0.27(0.75) \\
3.24(5.32)\end{array}$ & \\
\hline Mean (SD) injury test (days) & $5.95(4 \cdot 20)$ & $11 \cdot 8(8 \cdot 0)$ & $7 \cdot 12(5 \cdot 59)$ & \\
\hline \multicolumn{5}{|l|}{ Surgical treatment } \\
\hline \multicolumn{5}{|l|}{ Evacuation of } \\
\hline EDH & 0 & 2 & 2 & \\
\hline SDH & 0 & 2 & 2 & \\
\hline Repair depressed fracture & 0 & 2 & 2 & \\
\hline Insert Richmond bolt & 0 & 1 & 1 & \\
\hline
\end{tabular}

MVA = motor vehicle accident; $\mathrm{EDH}=$ epidural haematoma; $\mathrm{GCS}$ = Glasgow Coma Scale; SDH = subdural haematoma. ${ }^{\star}$ Overall comparison of head injured patients $v$ controls by one way analysis of variance revealed no differences in age or education.

and echo delay time (TE) of $32 \mathrm{msec}$; and a TR of $2000 \mathrm{msec}$ and a TE of 60 and $120 \mathrm{msec}$. A board-certified radiologist interpreted the neuroimaging findings independently of the neurobehavioural data. The CT and MRI findings, which were reviewed on different days, were coded on research forms which were compatible with computer entry. Intracranial abnormalities on MRI were coded as lesions provided that they were present on both the transaxial and coronal $\mathrm{T}_{2}$-weighted images (spin echo sequences: TR $2000 \mathrm{msec}$, TE 60 and $120 \mathrm{msec}$ ). The radiologist estimated the volume of each lesion in cubic centimetres by placing a grid on the area of interest. In cases with lesions consisting of more than one component (such as ring lesions) the constituent parts were summed to estimate a total volume.

Neurobehavioural examinations were performed at baseline during the initial hospitalisation (within 24 hours after the MRI scan) after resolution of post-traumatic amnesia ${ }^{13}$ and at one and three months after injury (table 1). The MRI (but not CT) was repeated on each follow up examination. Of the total series, 39 patients $(78 \%)$ returned for the one month follow up examination, whereas 11 patients $(22 \%)$ declined or were unable to return. Comparison of these subgroups disclosed no difference in demographic features. Patients who returned, however, had slightly less impaired consciousness as reflected by their lowest GCS score (mean 13.8, SD 1.7) than patients who did not return at one month (mean 12.2, SD 2.6, F $(1,48)=5.95, p<$ $0.02)$. Twenty six patients $(52 \%)$ returned for both the one month and three month follow up examinations.

\section{NEUROPSYCHOLOGICAL TESTS}

In view of the vulnerability of the orbitofrontal and temporal lobes to $\mathrm{CHI}^{14}$ the neurobehavioural examination emphasised func- tions dependent on the integrity of these areas. To evaluate frontal lobe functioning, the modified card sorting test ${ }^{16}$ of concept formation and flexibility in problem solving was given while measures of verbal fluency ${ }^{17}{ }^{18}$ (generation of words beginning with a designated letter within a time limit of 60 seconds) and design fluency ${ }^{19}$ (drawing novel designs under a time limit of five minutes) were also administered. Temporal lobe functioning was evaluated by the verbal selective reminding procedure, ${ }^{20}$ which tested recall of 12 words administered over 12 trials followed by a delayed recall trial 30 minutes later. Long term memory for relatively non verbal information was evaluated by recall of a spatial configuration of eight marbles on a board consisting of 16 locations. $^{21}$ On each of 12 trials the examiner corrected false-positive errors (marbles placed in incorrect locations) and reminded the patient of locations that had been missed on the preceding trial. Similar to verbal selective reminding, retention of the spatial locations was tested 30 minutes after completion of the 12 recall trials. Recognition memory for geometric and random designs ${ }^{22}$ was also assessed. The token test ${ }^{18}$ was used to assess the potential contribution of receptive language deficit to cognitive and memory performance.

\section{Results}

NEUROANATOMIC DISTRIBUTION OF ABNORMALITIES ON CT AND MRI

Of the total series 40 patients $(80 \%)$ had intracranial abnormalities (hyperintensities) visualised by the initial MRI, including 13 (26\%) who had normal CT findings, 26 (52\%) in whom MRI showed more lesions than were seen on CT, and a single patient who had identical findings on CT and MRI. In contrast, nine patients (18\%) had lesions on CT that were not seen on MRI, including eight 


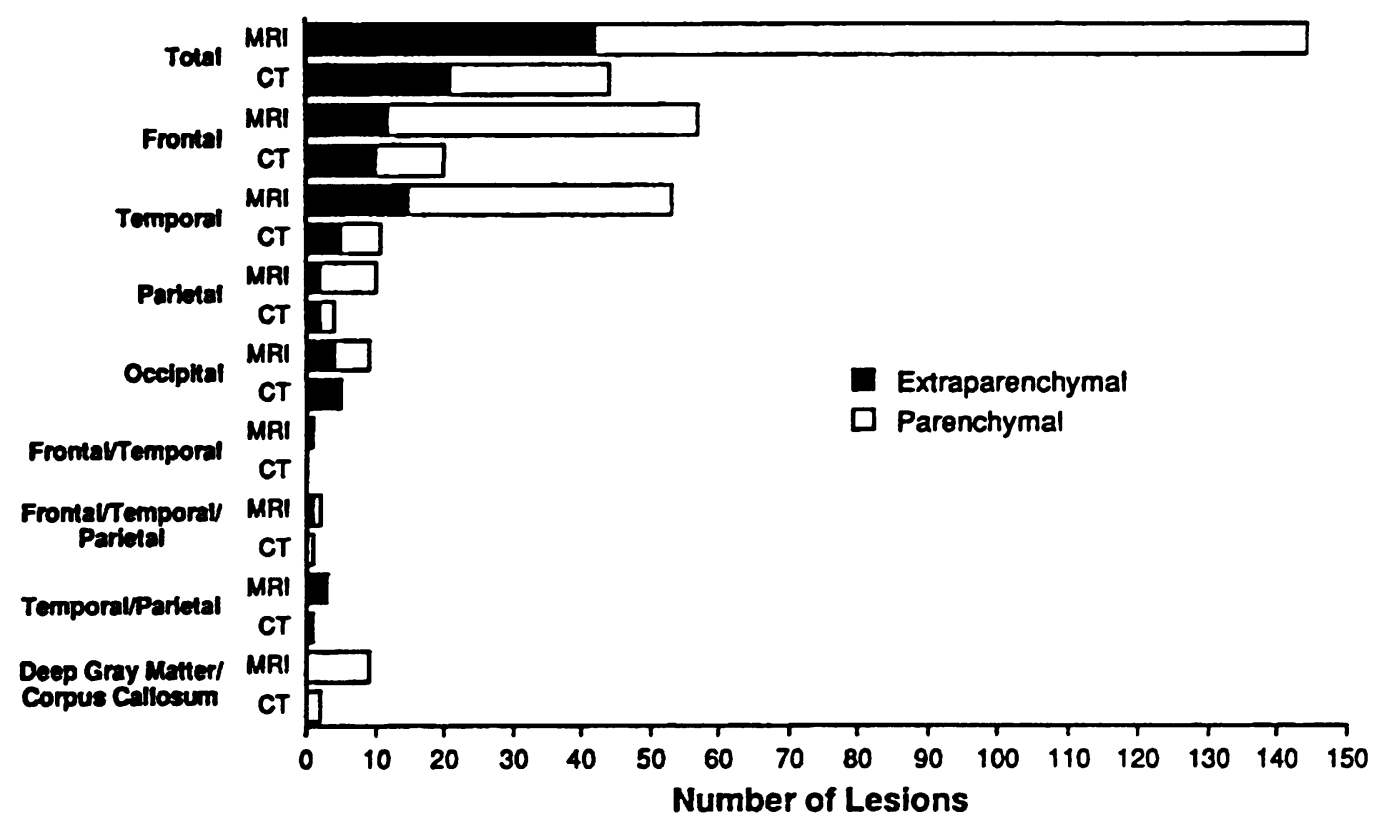

Figure 1 Incidence and neuroanatomical distribution of parenchymal and extraparenchymal lesions seen on MRI and CT at baseline plotted separately for patients with GCS scores in 13-15 (a) v 9-12 (b) ranges.

parenchymal lesions, three extraparenchymal (that is, subdural and extradural) lesions, and two cases of subarachnoid haemorrhage. Ten patients $(20 \%)$ had normal images on both CT and MRI.

Figure 1 depicts the number, type, and neuroanatomical distribution of lesions shown by CT and MRI at baseline for patients with GCS scores of 13-15 and 9-12. Of the 144 hyperintensities which were present on MRI, parenchymal abnormalities in the frontal and temporal region predominated with relatively few lesions in the parietal and occipital areas. Figure 1 also shows that lesions involving deep grey structures were rare in this series.

SIZE OF FOCAL LESION ON MRI IN RELATION TO IMPAIRED CONSCIOUSNESS AND TIME SINCE INJURY Figures $2 \mathrm{a}$ and $2 \mathrm{~b}$ plot the mean parenchymal and extraparenchymal lesion size separately for patients who had mild $v$ moderate impairment

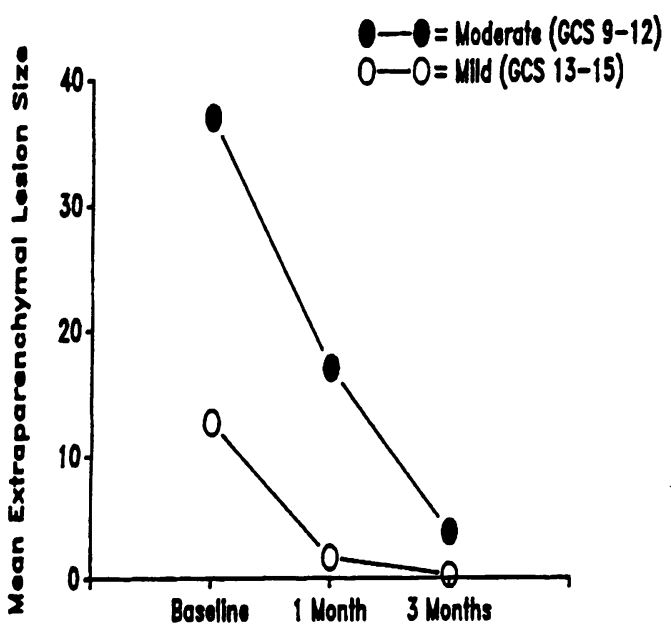

(a)

Figure 2 Mean size of (a) extraparenchymal lesions and (b) parenchymal lesions at baseline, one month, and three months in head injured patients sustaining mild to moderate impairment of consciousness according to Glasgow Coma Scale (GCS). Patients had lesions on baseline MRI. For GCS scores 13-15, baseline $n=9$, one month $n=5$, three months $n=4$.

of consciousness and underwent MRI at all three examinations. A dissociation between lesion size and impairment of consciousness was seen depending on whether the parenchymal or extraparenchymal compartments were affected. As shown in figure 2a extraparenchymal lesions at baseline were larger in patients who had moderate impairment of consciousness compared with patients with GCS scores in the 13-15 range $(F(1,38)=$ $4.11, p<0.05)$. This relation between impaired consciousness and extraparenchymal lesion size was confirmed at one month ( $F(1$, $30)=8.99, \mathrm{p}<0.005)$ and three months $(\mathrm{F}$ $(1,32)=4.38, p<0.05)$. In contrast the groups defined by GCS score did not differ in size of parenchymal lesion at baseline or follow up (figure 2B). The group with GCS scores of 9-12 included large extraparenchymal lesions $(50 \mathrm{cc}, 100 \mathrm{cc}, 150 \mathrm{cc})$ that were not surgically evacuated in three patients.

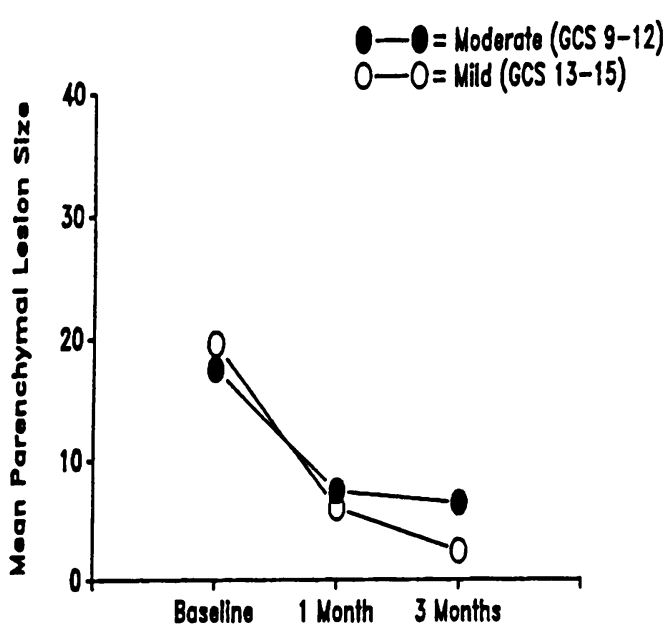

(b)
parenchymal lesions at baseline, one month, and three
scores $13-15$, baseline $n=9$, one month $n=5$, three 
Table 2 Relationship between site of cerebral abnormality on MRI and neurobehavioural findings at baseline

\begin{tabular}{|c|c|c|c|c|c|}
\hline & \multicolumn{3}{|c|}{ Localisation of injury } & \multirow[b]{2}{*}{$\begin{array}{l}\text { Controls } \\
(n=21)\end{array}$} & \multirow[b]{2}{*}{$F$ value } \\
\hline & $\begin{array}{l}\text { Frontal } \\
(n=8)\end{array}$ & $\begin{array}{l}\text { Temporal } \\
(n=5)\end{array}$ & $\begin{array}{l}\text { Frontotemporal } \\
(n=11)\end{array}$ & & \\
\hline \multicolumn{6}{|l|}{ Severity of injury } \\
\hline $\begin{array}{l}\text { GCS score } \\
\text { Time to obey commands (days) } \\
\text { Duration of PTA (days) }\end{array}$ & $\begin{array}{r}13.62(1.92) \\
0.37(1.05) \\
2.00(2.44)\end{array}$ & $\begin{array}{l}13.20(2.04) \\
0.60(1.34) \\
6.80(10.98)\end{array}$ & $\begin{array}{r}13.80(1 \cdot 16) \\
0.03(0.08) \\
3.54(5 \cdot 00)\end{array}$ & & $\begin{array}{l}0 \cdot 24 \\
0 \cdot 86 \\
0 \cdot 89\end{array}$ \\
\hline Lesion size $(\mathrm{cc})$ & & & & & \\
\hline $\begin{array}{l}\text { Parenchymal } \\
\text { Extraparenchymal }\end{array}$ & $\begin{array}{r}16 \cdot 37(17 \cdot 54) \\
9 \cdot 12(13 \cdot 53)\end{array}$ & $\begin{array}{l}8 \cdot 80(6 \cdot 70) \\
4 \cdot 00(8 \cdot 94)\end{array}$ & $\begin{array}{l}18 \cdot 50(17 \cdot 18) \\
12 \cdot 36(10 \cdot 74)\end{array}$ & & $\begin{array}{l}0.65 \\
0.92\end{array}$ \\
\hline \multicolumn{6}{|l|}{$\begin{array}{l}\text { Frontal lobe functioning } \\
\text { Card Sorting }\end{array}$} \\
\hline $\begin{array}{l}\text { Total correct } \\
\% \text { Perseverative errors } \\
\text { Word association score } \\
\text { Perseverative errors } \\
\text { Design fluency (fixed) }\end{array}$ & $\begin{array}{c}33 \cdot 38(7 \cdot 78) \\
5 \cdot 11(6 \cdot 59) \\
27 \cdot 13(10 \cdot 20)^{a} \\
1 \cdot 00(2 \cdot 14)\end{array}$ & $\begin{array}{l}25 \cdot 80(10 \cdot 35)^{a} \\
14 \cdot 61(15 \cdot 77) \\
23 \cdot 20(14 \cdot 72)^{b} \\
1 \cdot 20(1.64)\end{array}$ & $\begin{array}{l}28.00(10.81)^{\mathrm{b}} \\
13.39(17.21)^{\mathrm{a}} \\
23.36(9.93)^{\mathrm{c}} \\
1.91(4.21)\end{array}$ & $\begin{array}{c}36.43(2.52)^{\mathrm{ab}} \\
2.21(3.30)^{\mathrm{a}} \\
43.33(11.28)^{\mathrm{abc}} \\
0.33(0.80)\end{array}$ & $\begin{array}{l}4 \cdot 94^{\star \star} \\
3 \cdot 80^{\star} \\
10 \cdot 69^{\star \star \star} \\
1 \cdot 08\end{array}$ \\
\hline $\begin{array}{l}\text { \% Perseverative errors } \\
\text { Memory }\end{array}$ & $26.08(26 \cdot 24)^{2}$ & $18 \cdot 22(13 \cdot 73)$ & $13 \cdot 74(11 \cdot 25)$ & $3 \cdot 12(5 \cdot 55)^{2}$ & $6 \cdot 28^{\star \star}$ \\
\hline \multicolumn{6}{|l|}{$\begin{array}{l}\text { Memory } \\
\text { Recall }\end{array}$} \\
\hline $\begin{array}{l}\text { Verbal CLTR (total words) } \\
\text { Verbal 30' recall } \\
\text { Spatial CLTR }\end{array}$ & $\begin{array}{r}44 \cdot 88(45 \cdot 80)^{2} \\
6 \cdot 25(3 \cdot 37)^{2}\end{array}$ & $\begin{array}{l}39 \cdot 00(42 \cdot 77)^{\mathrm{b}} \\
4 \cdot 60(5 \cdot 27)^{\mathrm{b}}\end{array}$ & $\begin{array}{l}37 \cdot 00(34 \cdot 74)^{c} \\
6.50(5 \cdot 19)^{c}\end{array}$ & $\begin{array}{c}119 \cdot 81(17 \cdot 76)^{\mathrm{abc}} \\
11.76(0 \cdot 43)^{\mathrm{abc}}\end{array}$ & $\begin{array}{l}24 \cdot 22^{\star \star \star} \\
11 \cdot 51^{\star \star \star}\end{array}$ \\
\hline $\begin{array}{l}\text { (total locations) } \\
\text { Spatial 30' recall }\end{array}$ & $\begin{array}{c}67 \cdot 87(31.97) \\
6.75(1 \cdot 38)\end{array}$ & $\begin{aligned} 59 \cdot 80 & (27 \cdot 68) \\
6.80 & (1 \cdot 64)\end{aligned}$ & $\begin{array}{l}65.80(33.37)^{a} \\
6.77(1.30)\end{array}$ & $\begin{array}{c}89.95(8.78)^{2} \\
7.80(0.67)\end{array}$ & $\begin{array}{l}4 \cdot 24^{\star \star} \\
3 \cdot 19^{\star}\end{array}$ \\
\hline $\begin{array}{l}\text { Recognition } \\
\text { Geometric (net score) } \\
\text { Random (net score) }\end{array}$ & $\begin{array}{l}24 \cdot 57(4 \cdot 85) \\
11 \cdot 28(5 \cdot 40)\end{array}$ & $\begin{array}{l}15 \cdot 00(14 \cdot 25)^{a} \\
11.75(11 \cdot 14)\end{array}$ & $\begin{array}{r}16.00(8.50)^{\mathrm{b}} \\
3.55(5 \cdot 87)^{\mathrm{a}}\end{array}$ & $\begin{array}{l}25 \cdot 71(3 \cdot 75)^{\mathrm{ab}} \\
17 \cdot 47(5 \cdot 36)^{\mathrm{a}}\end{array}$ & $\begin{array}{r}6 \cdot 51^{\star \star \star} \\
11 \cdot 00^{\star \star \star}\end{array}$ \\
\hline $\begin{array}{l}\text { Language comprehension } \\
\text { Token test }\end{array}$ & $40 \cdot 00(4 \cdot 44)$ & $39.40(5 \cdot 46)$ & $38.90(4.50)^{n}$ & $43.33(0.97)^{2}$ & $5 \cdot 17^{\star \star}$ \\
\hline
\end{tabular}

Restricting the analysis of lesion to those patients who returned for follow up examination showed significant reductions in lesion size, particularly during the first month, whereas changes between one and three months were less impressive (see figs $2 a$ and $2 b)$. Overall analysis of parenchymal and extraparenchymal lesions showed that the change in lesion size from baseline to one month was highly significant $(F(1,36)=8.32$, $\mathrm{p}<0.006)$. In contrast the reduction in lesion size between one and three months fell short of significance. Although the interaction between severity of impaired consciousness (GCS score 9-12 v 13-15) and occasion was significant (F $(2,51)=3.39, p<0.04)$, a "floor" effect was present as the lesions were essentially resolved by three months irrespective of the intial GCS score. The triple interaction of GCS score with occasion and type of lesion was not significant.

SITE OF PARENCHYMAL ABNORMALITY IN RELATION TO NEUROBEHAVIOURAL SEQUELAE AND RECOVERY In view of the predominance of focal hyperintensities in the frontal and temporal regions, subgroups of $\mathrm{CHI}$ patients were formed according to sites of lesions on the baseline MRI (table 2). The frontal and temporal lobe groups in table 2 included patients with lesions confined to one of these regions, whereas patients with overlapping lesions were classified as frontotemporal. Table 2 also shows that there were no differences in the acute neurological indices of the frontal, temporal, and frontotemporal groups. Nine patients with lesions affecting the frontal region and seven patients with temporal lobe involvement were deleted from the analysis of site effects because their lesions extended outside of the frontotemporal region, including the parietal (5), occipital (5), parieto-occipital (4), internal capsule (1), and superior sagittal sinus (1). The 10 patients who had no evidence of brain lesion on the baseline MRI (10) were also excluded from this analysis.

NEUROBEHAVIOURAL FINDINGS AT BASELINE

Analysis of the baseline data disclosed neuropsychological impairment in all three of the lesion site groups relative to normal subjects (see table 2). Deficits on tests of frontal lobe dysfunction are reflected by a higher percentage of perseverative errors on word association or design fluency, or both, in all three groups. Although performance of the $\mathrm{CHI}$ patients on the modified card sorting test tended to fall below the controls, the difference reached significance only for the temporal and frontotemporal lesion groups. Impaired verbal recall (verbal CLTR in table 2) was confirmed for the total CHI series and in all three groups, whereas defective reproduction of a visuospatial array from memory (spatial CLTR) was confined to the frontotemporal group. Table 2 shows that recognition memory for designs was impaired in the temporal and frontotemporal lesion groups. In summary, the baseline findings showed pervasive impairment on tests of cognition and memory without consistent relations between specific neurobehavioural deficits and site of lesion. In view of the possibility that subacute diffuse brain swelling or oedema might have obscured the more restricted effects of focal lesions on the baseline examination, we performed a similar analysis on the MRI and neurobehavioural data collected at one month. 
Table 3 Proportion of test scores for executive function and memory domains falling below 95\% of controls in patients grouped according to MRI findings at one month

\begin{tabular}{|c|c|c|c|c|c|c|c|c|}
\hline \multirow[b]{2}{*}{ Patient } & \multirow[b]{2}{*}{ One month } & \multirow[b]{2}{*}{ Baseline } & \multicolumn{2}{|c|}{ Type of test at baseline } & \multicolumn{2}{|c|}{ Type of test at one month } & \multicolumn{2}{|c|}{ Type of test at three months } \\
\hline & & & $\begin{array}{l}\text { Executive } \\
\text { function }\end{array}$ & Memory & $\begin{array}{l}\text { Executive } \\
\text { function }\end{array}$ & Memory & $\begin{array}{l}\text { Executive } \\
\text { function }\end{array}$ & Memory \\
\hline $\begin{array}{l}1 \\
2 \\
3 \\
4 \\
5 \\
6 \\
7 \\
7 \\
8 \\
9\end{array}$ & $\begin{array}{l}\text { F-R } \\
\text { F-B } \\
\text { F-B } \\
\text { F-B } \\
\text { F-L } \\
\text { F-B } \\
\text { F-L } \\
\text { F-R } \\
\text { F-B }\end{array}$ & $\begin{array}{l}\text { FT-B } \\
\text { F-B } \\
\text { O-B } \\
\text { FT-B } \\
\text { FT-B } \\
\text { F-B } \\
\text { F-L } \\
\text { FT-B } \\
\text { O-B }\end{array}$ & $\begin{array}{l}0.00 \\
0.50 \\
1.00 \\
0.25 \\
0.50 \\
0.75 \\
0.50 \\
0.25 \\
0.25\end{array}$ & $\begin{array}{l}\quad \text { Frontal } \\
0.75 \\
0.50 \\
0.75 \\
0.50 \\
0.25 \\
0.50 \\
0.25 \\
0.50 \\
0.25\end{array}$ & $\begin{array}{l}0.50 \\
0.00 \\
0.75 \\
0.25 \\
0.00 \\
0.00 \\
0.25 \\
0.25 \\
0.00\end{array}$ & $\begin{array}{l}0 \cdot 50 \\
0 \cdot 00 \\
0 \cdot 50 \\
0 \cdot 25 \\
0 \cdot 25 \\
0 \cdot 25 \\
0 \cdot 00 \\
0 \cdot 75 \\
0 \cdot 50\end{array}$ & $\begin{array}{l}0.50 \\
\overline{0.75} \\
\overline{-} \\
\overline{0.00} \\
0.00 \\
0.00 \\
-\end{array}$ & $\begin{array}{l}0.25 \\
\overline{0 \cdot 25} \\
- \\
= \\
\overline{-} \\
-25\end{array}$ \\
\hline $\begin{array}{l}1 \\
2 \\
3 \\
4\end{array}$ & $\begin{array}{l}\text { T-B } \\
\text { T-L } \\
\text { T-R } \\
\text { T-R }\end{array}$ & $\begin{array}{l}\text { O-B } \\
\text { T-L } \\
\text { FT-R } \\
\text { FT-B }\end{array}$ & $\begin{array}{l}0.25 \\
1.00 \\
0.75 \\
1.00\end{array}$ & $\begin{array}{l}\text { Tempore } \\
0.75 \\
1.00 \\
1.00 \\
0.75\end{array}$ & $\begin{array}{l}n .25 \\
0.25 \\
0.50 \\
0.50\end{array}$ & $\begin{array}{l}0.25 \\
0.25 \\
0.50 \\
0.00\end{array}$ & $\begin{array}{l}\overline{0.25} \\
0.50 \\
-\end{array}$ & $\begin{array}{l}\overline{0.25} \\
0.50 \\
-\end{array}$ \\
\hline $\begin{array}{l}1 \\
2 \\
3 \\
4\end{array}$ & $\begin{array}{l}\text { FT-B } \\
\text { FT-B } \\
\text { FT-B } \\
\text { FT-R }\end{array}$ & $\begin{array}{l}\text { O-B } \\
\text { O-B } \\
\text { O-B } \\
\text { FT-R }\end{array}$ & $\begin{array}{l}1.00 \\
0.25 \\
0.50 \\
1.00\end{array}$ & $\begin{array}{l}\text { Frontotemp } \\
1.00 \\
0.25 \\
0.50 \\
0.50\end{array}$ & $\begin{array}{l}\text { sion } \\
0 \cdot 25 \\
0.25 \\
0.50 \\
0.25\end{array}$ & $\begin{array}{l}0.50 \\
0.25 \\
0.75 \\
0.00\end{array}$ & $\begin{array}{l}0 \cdot 25 \\
\overline{0.25} \\
0 \cdot 50\end{array}$ & $\begin{array}{l}0.25 \\
0.75 \\
0.00\end{array}$ \\
\hline $\begin{array}{l}1 \\
2 \\
3 \\
4 \\
5 \\
6 \\
7 \\
8\end{array}$ & $\begin{array}{l}\text { Resolved } \\
\text { Resolved } \\
\text { Resolved } \\
\text { Resolved } \\
\text { Resolved } \\
\text { Resolved } \\
\text { Resolved } \\
\text { Resolved }\end{array}$ & $\begin{array}{l}\text { F-L } \\
\text { FT-B } \\
\text { T-L } \\
\text { T-L } \\
\text { F-L } \\
\text { O-B } \\
\text { FT-B } \\
\text { F-B }\end{array}$ & $\begin{array}{l}0.25 \\
0.75 \\
0.50 \\
0.25 \\
1.00 \\
0.00 \\
0.50 \\
0.50\end{array}$ & $\begin{array}{l}\quad \text { Resolvec } \\
0.00 \\
1.00 \\
1.00 \\
0.25 \\
0.50 \\
0.50 \\
0.75 \\
0.75\end{array}$ & $\begin{array}{l}0.00 \\
0.50 \\
0.75 \\
0.00 \\
0.50 \\
0.33 \\
0.25 \\
0.50\end{array}$ & $\begin{array}{l}0.00 \\
0.50 \\
0.50 \\
0.00 \\
0.25 \\
0.25 \\
0.25 \\
0.25\end{array}$ & $\begin{array}{l}0.00 \\
0.25 \\
0.66 \\
0.00 \\
0.25 \\
\overline{0.50} \\
-\end{array}$ & $\begin{array}{l}0.00 \\
0.50 \\
0.75 \\
0.00 \\
0.00 \\
- \\
0.50 \\
-\end{array}$ \\
\hline $\begin{array}{l}1 \\
2 \\
3 \\
4 \\
5 \\
6\end{array}$ & $\begin{array}{l}\text { O-L } \\
\text { O-R } \\
\text { O-L } \\
\text { O-L } \\
\text { O-B } \\
\text { O-R }\end{array}$ & $\begin{array}{l}\text { O-L } \\
\text { O-B } \\
\text { O-B } \\
\text { O-B } \\
\text { O-B } \\
\text { T-R }\end{array}$ & $\begin{array}{l}0.25 \\
0.50 \\
0.00 \\
0.00 \\
0.50 \\
0.50\end{array}$ & $\begin{array}{l}\quad \text { Other } \\
0.25 \\
0.50 \\
0.00 \\
0.00 \\
0.25 \\
1.00\end{array}$ & $\begin{array}{l}0.25 \\
0.25 \\
0.50 \\
0.50 \\
0.25 \\
0.25\end{array}$ & $\begin{array}{l}0.00 \\
0 \cdot 25 \\
0 \cdot 00 \\
0 \cdot 25 \\
0.25 \\
0.25\end{array}$ & $\begin{array}{l}025 \\
\overline{0} \cdot 00 \\
0 \cdot 00 \\
0.50 \\
0.00\end{array}$ & $\begin{array}{l}0.00 \\
0.00 \\
0.00 \\
0.25 \\
0.25\end{array}$ \\
\hline $\begin{array}{l}1 \\
2 \\
3 \\
4 \\
5 \\
6 \\
7 \\
8\end{array}$ & & & $\begin{array}{l}0.00 \\
0.00 \\
0.25 \\
0.00 \\
0.50 \\
0.50 \\
0.25 \\
0.25\end{array}$ & $\begin{array}{l}\quad \text { No le } \\
0.50 \\
0.50 \\
0.25 \\
0.25 \\
0.33 \\
0.25 \\
0.25 \\
0.25\end{array}$ & $\begin{array}{l}0.00 \\
0 \cdot 50 \\
0 \cdot 00 \\
0 \cdot 00 \\
0 \cdot 00 \\
0 \cdot 25 \\
0 \cdot 50 \\
0 \cdot 00\end{array}$ & $\begin{array}{l}0.25 \\
0 \cdot 00 \\
0 \cdot 00 \\
0 \cdot 00 \\
0 \cdot 00 \\
0 \cdot 00 \\
0 \cdot 00 \\
0.25\end{array}$ & $\begin{array}{l}0.00 \\
0.25 \\
0.00 \\
\overline{0.50} \\
\overline{0.25}\end{array}$ & $\begin{array}{l}0.00 \\
0.00 \\
0.00 \\
\overline{0.25} \\
\overline{0.00} \\
-\end{array}$ \\
\hline
\end{tabular}

$\mathrm{B}=$ bilateral; $\mathrm{F}=$ frontal; $\mathrm{L}=$ left; $\mathrm{R}=$ right; $\mathrm{T}=$ temporal.

NEUROBEHAVIOURAL FINDINGS AT ONE AND THREE MONTHS AFTER INJURY IN RELATION TO SERIAL MRI DATA

Comparison of the one month and baseline MRI findings showed a pattern of changes in the site of lesion (table 3). Frontotemporal hyperintensities tended to resolve to lesions confined to the frontal or temporal regions whereas multifocal lesions changed to frontotemporal lesions. Multifocal abnormalities at baseline (denoted by other lesion group) tended to partially resolve from bilateral to unilateral lesions. Most of the patients with complete resolution of lesions by one month had initial findings restricted to the frontal or temporal region. Analysis of the follow up neurobehavioural data confirmed the persistence of deficits relative to control subjects on several measures of frontal lobe functioning and memory. Site of lesion based on the one month MRI in the 39 patients who returned for follow up often differed from their baseline findings (table 3). Patients whose lesions had resolved were deleted from the comparison of the groups with the one month data. Repeating the group comparisons with the one month data still failed to demonstrate impressive differences in neurobehavioural functioning (table 4). Similarly, comparison of the frontal, temporal, and frontotemporal lesion groups at three months (not shown) again showed no effect for site of lesion.

Table 3 summarises for individual patients (grouped according to site of lesion at one month) the proportion of test scores which fell below the 5th percentile of the control group on measures of frontal ("executive") function and memory. A trend of multiple deficits on the baseline examination changing to more focused impairments at one and three months after injury was evident. Patients with residual lesions which affected areas outside of the frontotemporal region, however, also exhibited persistent neurobehavioural deficits (table 4). Six of the nine patients whose lesions resolved by one month, nevertheless continued to exhibit deficits on tests of executive and memory functioning. In contrast, none of the seven patients without MRI evidence of an intracranial lesion at baseline or follow up had defective scores on both the executive function and memory domains one month after injury. Comparison of the one month neuropsychological performance of patients with resolved 
Table 4 Relation between site of cerebral abnormality on one month MRI and concurrent neurobehavioural findings

\begin{tabular}{|c|c|c|c|c|c|}
\hline & \multicolumn{3}{|l|}{ Localisation group } & \multirow[b]{2}{*}{$\begin{array}{l}\text { Controls } \\
(n=21)\end{array}$} & \multirow[b]{2}{*}{$F$ value } \\
\hline & $\begin{array}{l}\text { Frontal } \\
(n=9)\end{array}$ & $\begin{array}{l}\text { Temporal } \\
(n=4)\end{array}$ & $\begin{array}{l}\text { Frontotemporal } \\
(n=4)\end{array}$ & & \\
\hline \multicolumn{6}{|c|}{ Frontal lobe functioning } \\
\hline $\begin{array}{l}\text { Card sorting } \\
\text { Total correct } \\
\% \text { Perseverative errors } \\
\text { Word association score } \\
\text { Perseverative errors } \\
\text { Desion fluency (fixed) }\end{array}$ & $\begin{array}{r}37.35(1.50) \\
1.73(2.99) \\
33.22(8.75) \\
0.77(0.83)\end{array}$ & $\begin{array}{c}35.00(7 \cdot 61) \\
2.60(3 \cdot 12) \\
26 \cdot 25(9 \cdot 53)^{\circ} \\
0.25(0.50)\end{array}$ & $\begin{array}{c}35 \cdot 75(3.68) \\
4.33(4 \cdot 77) \\
27 \cdot 00(4.96)^{b} \\
0.25(0.50)\end{array}$ & $\begin{array}{l}36.42(2.52) \\
2.21(3.30) \\
43.33(11.28)^{\mathrm{ab}} \\
0.33(0.79)\end{array}$ & $\begin{array}{l}0 \cdot 67 \\
0.59 \\
5 \cdot 90^{\star \star} \\
0 \cdot 89\end{array}$ \\
\hline$\%$ Perseverative errors & $8.86(9.96)$ & $5 \cdot 95(7 \cdot 89)$ & $0.00(0.00)$ & $3 \cdot 12(5 \cdot 55)$ & 1.98 \\
\hline $\begin{array}{l}\text { Verbal CLTR (total words) } \\
\text { Verbal 30' recall } \\
\text { Spatial CLTR (total locations) } \\
\text { Spatial 30' recall } \\
\text { Recognition }\end{array}$ & $\begin{array}{l}85 \cdot 77(33 \cdot 03)^{n} \\
10 \cdot 22(2 \cdot 58) \\
81.55(27 \cdot 16) \\
7 \cdot 77(0.66)\end{array}$ & $\begin{array}{l}\text { Memc } \\
80.25(31.47) \\
10.00(0.81) \\
94.00(2.16) \\
7.75(0.50)\end{array}$ & $\begin{array}{l}74.00(60.74)^{b} \\
9.00(3.55)^{a^{2}} \\
95.50(1.00) \\
8.00(0.00)\end{array}$ & $\begin{array}{c}119.80(17.75)^{\mathrm{ab}} \\
11.76(0.43)^{\mathrm{a}} \\
89.95(8.79) \\
7.80(0.67)\end{array}$ & $\begin{array}{l}5 \cdot 47^{\star \star} \\
4 \cdot 35^{\star \star} \\
1 \cdot 19 \\
0 \cdot 14\end{array}$ \\
\hline $\begin{array}{l}\text { Geometric (net score) } \\
\text { Random (net score) }\end{array}$ & $\begin{array}{l}25.88(3.44) \\
14.00(7.53)\end{array}$ & $\begin{array}{l}26.50(2.38) \\
19.50(9 \cdot 70)^{*}\end{array}$ & $\begin{array}{r}17.00(16.52) \\
2.33(10.01)^{\mathrm{ab}}\end{array}$ & $\begin{array}{l}25.71(3.75) \\
17.47(3.56)^{b}\end{array}$ & $\begin{array}{l}2 \cdot 55 \\
4 \cdot 99^{\star \star}\end{array}$ \\
\hline \multicolumn{6}{|c|}{ Language comprehension } \\
\hline
\end{tabular}

${ }^{\star} \mathrm{p}<0.05$.

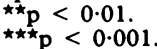

F value pertains to overall effect of groups whereas common superscripts $\left({ }^{\text {abc }}\right)$ denote significant contrasts between two groups.
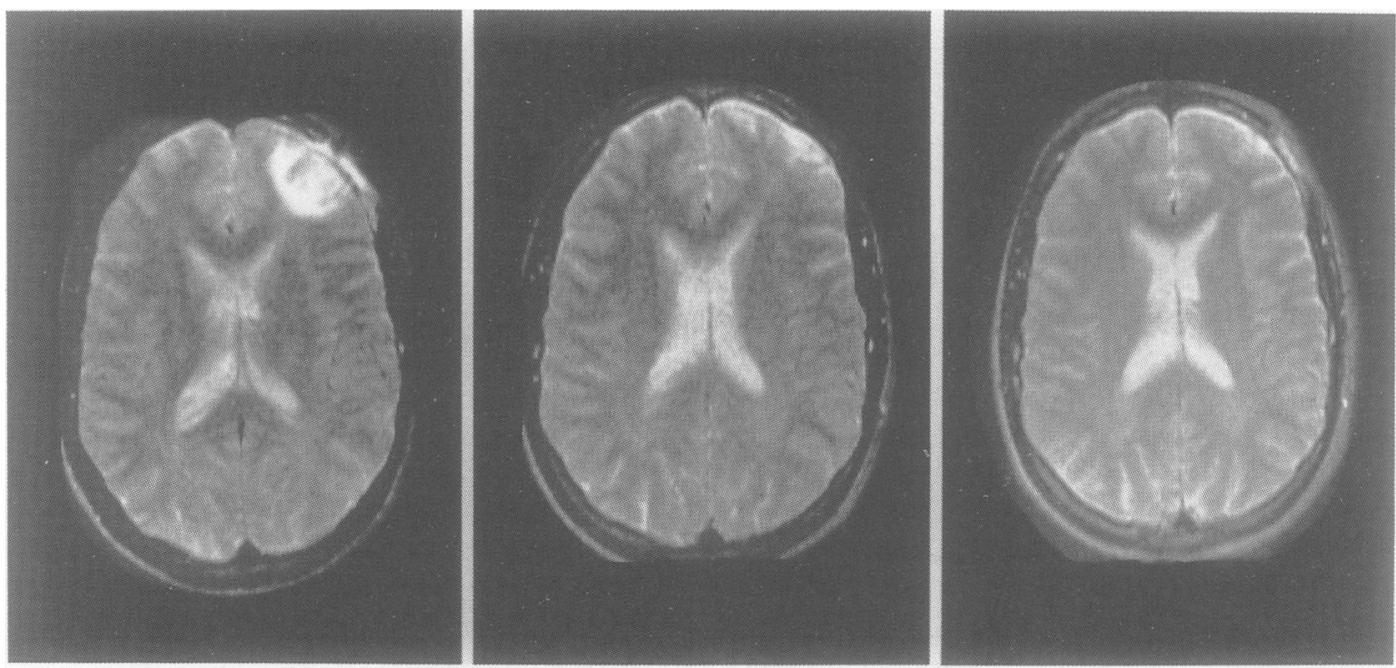

(a)

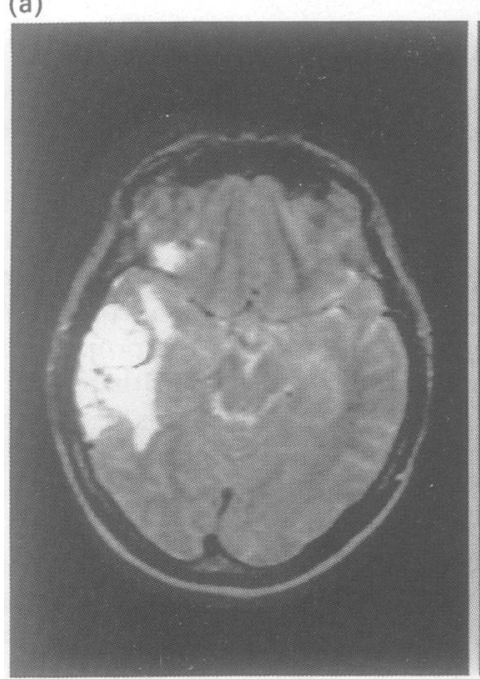

(b)

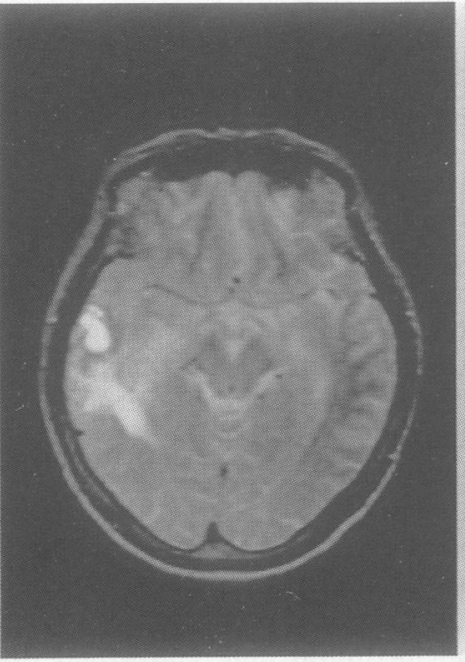

one month

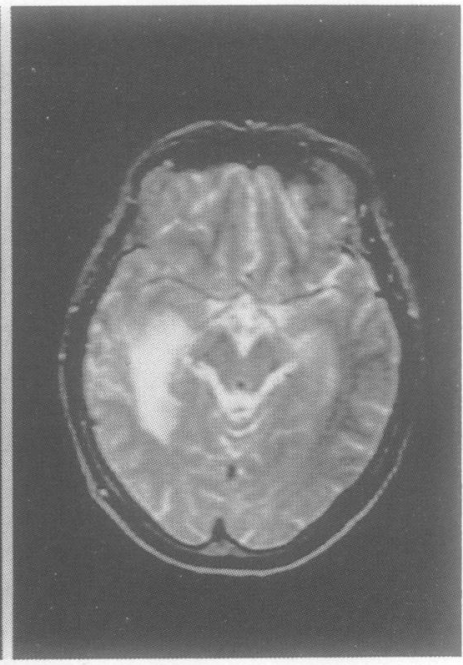

three months

Figure 3a MRI of patient 7 of frontal group (see table 4), 27 year old man whose initial GCS score was 14 after sustaining CHI when struck by tow line under high tension. Baseline MRI performed three days after injury showed area of increased signal $(33 \mathrm{cc}$ ) in left frontal cortex, interpreted as contusion. Follow up MRI showed clear resolution of lesion. Neurobehavioural findings at one month reflected specific problem in verbal fluency which resolved by three months. (b) MRI obtained from patient 4 of the frontotemporal group (see table 4), 41 year old woman who sustained CHI when struck by car. Despite GCS score of 13 indicating mild impairment of consciousness, post-traumatic amnesia persisted for 17 days. Large predominantly right temporal contusion/haematoma (60 cc) detected on baseline MRI was partially resolved on follow up scans. Patient's initial memory deficit resolved, but she still showed defects on tests of executive function at one and three months. 
Table 5 Pearson correlation coefficients $(r)$ between duration of post-traumatic amnesia and neurobehavioural performance*

\begin{tabular}{|c|c|c|c|c|c|c|}
\hline & \multicolumn{2}{|c|}{ Baseline $(n=50)$} & \multicolumn{2}{|c|}{ One month $(n=39)$} & \multicolumn{2}{|c|}{ Three months $(n=26)$} \\
\hline & $r$ & $p$ value & $r$ & p value & $r$ & $p$ value \\
\hline \multicolumn{7}{|c|}{ Frontal lobe functioning } \\
\hline $\begin{array}{l}\text { Card sorting } \\
\text { Total correct } \\
\text { \% Perseverative errors } \\
\text { Word association score } \\
\text { Perseverative errors } \\
\text { Design fluency (fixed) }\end{array}$ & $\begin{array}{r}-0.51 \\
0.49 \\
-0.32 \\
0.07\end{array}$ & $\begin{array}{l}0.0002 \\
0.0004 \\
0.03 \\
0.65\end{array}$ & $\begin{array}{r}-0.25 \\
0.04 \\
-0.51 \\
-0.01\end{array}$ & $\begin{array}{l}0.13 \\
0.82 \\
0.0008 \\
0.98\end{array}$ & $\begin{array}{r}-0 \cdot 24 \\
0 \cdot 23 \\
-0.36 \\
-0.29\end{array}$ & $\begin{array}{l}0.23 \\
0.25 \\
0.06 \\
0.14\end{array}$ \\
\hline$\%$ Perseverative errors & $0 \cdot 17$ & 0.25 & 0.02 & 0.91 & 0.02 & 0.92 \\
\hline \multicolumn{7}{|c|}{ Memory } \\
\hline $\begin{array}{l}\text { Verbal CLTR (total words) } \\
\text { Verbal 30' recall } \\
\text { Spatial CLTR (total locations) } \\
\text { Spatial 30' recall }\end{array}$ & $\begin{array}{l}-0.38 \\
-0.47 \\
-0.44 \\
-0.38\end{array}$ & $\begin{array}{l}0.008 \\
0.0007 \\
0.002 \\
0.01\end{array}$ & $\begin{array}{l}-0.52 \\
-0.40 \\
-0.33 \\
-0.34\end{array}$ & $\begin{array}{l}0.0007 \\
0.01 \\
0.04 \\
0.04\end{array}$ & $\begin{array}{l}-0 \cdot 34 \\
-0 \cdot 23 \\
-0.67 \\
-0.12\end{array}$ & $\begin{array}{l}0 \cdot 08 \\
0 \cdot 24 \\
0 \cdot 0001 \\
0.53\end{array}$ \\
\hline $\begin{array}{l}\text { Recognition } \\
\text { Geometric (net score) } \\
\text { Random (net score) }\end{array}$ & $\begin{array}{l}-0.57 \\
-0.27\end{array}$ & $\begin{array}{l}0.0001 \\
0.09\end{array}$ & $\begin{array}{l}-0.24 \\
-0.24\end{array}$ & $\begin{array}{l}0.15 \\
0.15\end{array}$ & $\begin{array}{l}-0.29 \\
-0.19\end{array}$ & $\begin{array}{l}0.13 \\
0.33\end{array}$ \\
\hline Token test & -0.42 & $\begin{array}{c}\text { Langu } \\
0.003\end{array}$ & $\begin{array}{c}\text { mprehensi } \\
-0.36\end{array}$ & 0.03 & $-0 \cdot 11$ & 0.58 \\
\hline
\end{tabular}

CLTR = consistent long term retrieval.

Minor variation in sample size across different tests due to scheduling and equipment problems.

lesions $v$ the group who had consistently normal MRI findings showed that verbal memory was impaired in the patients who had transient lesions $(F(1,14)=7.12, p<0.02)$. There were no other differences in neuropsychological performance, however, between the resolved and no lesion groups.

The transition from pervasive to specific neurobehavioural sequelae by one month after injury is illustrated by the findings of two patients. Figure 3a shows the MRI scan obtained at baseline in patient 7 of the frontal group (table 3) who had a left frontal lesion which was still present at one month. As summarised in table 3 there was considerable resolution of his multiple deficits by one month, leaving him with a specific verbal dysfluency. Figure $3 \mathrm{~b}$ depicts a predominantly right temporal lobe lesion in patient 4 of the frontotemporal group whose neurobehavioural findings evolved from pervasive deficits initially to a specific impairment on measures of executive function by one month.

RELATION BETWEEN DURATION OF POSTTRAUMATIC AMNESIA AND NEUROBEHAVIOURAL FINDINGS

The duration of post-traumatic amnesia corresponded to the interval beginning when the patient began to obey commands until attaining normal scores on a brief test ${ }^{13}$ of orientation and memory for ongoing events. Table 5 depicts the Pearson correlation coefficients between duration of amnesia and the neuropsychological test scores at each examination. The most consistently significant correlations across the three examinations were obtained for the verbal and visuospatial selective reminding tests of multitrial recall. In contrast the correlations for recognition memory and executive function were greatly diminished by the three month examination.

\section{Discussion}

Our findings confirm our preliminary data ${ }^{8}$ and studies at other centres, ${ }^{1-7}$ indicating that intracranial hyperintensities are more often present on MRI compared with focal CT abnormalities in patients sustaining mild to moderate CHI. Our initial report ${ }^{8}$ showed focal lesions in 17 of 20 patients (85\%) studied during the first week after sustaining mild to moderate head injury, a figure which closely approximates the present MRI finding of focal abnormalities in 40 of 50 cases $(\mathbf{8 0 \%})$. Parenchymal lesions on MRI were distributed primarily in the frontotemporal region, a pattern consistent with neuropathological findings in fatal head injuries ${ }^{14}$ and experimental models of CHI. ${ }^{15}$ Our study also shows that moderate impairment of consciousness rather than mild confusion or disorientation is associated with larger intracranial lesions on the one month MRI (but not at baseline). The size of parenchymal lesion, however, was not related to the severity of impaired consciousness.

Our preliminary observations ${ }^{8}$ had suggested that the pattern of initial neurobehavioural deficits was related to a frontal $v$ temporal site of lesion detected by MRI. In this expanded study neurobehavioural deficits on the baseline examination were pervasive on tests of purported frontal lobe function and on measures of memory irrespective of whether the intracranial lesion was confined to the frontal or temporal lobes or overlapped these regions. The relation of focal brain lesions to specific neurobehavioural sequelae one month after injury also showed inconsistencies across patients. Individual patients with resolved lesions in the frontotemporal region, however, tended to have a higher proportion of tests with defective scores than patients who had no lesions on their initial MRI. The inconsistent relation between site of lesion and pattern of neurobehavioural deficit did not change appreciably over three months in our patients with mild to moderate $\mathrm{CHI}$. The small number of patients in the lesion site groups, however, is a limitation of the present study because of the reduced power of the statistical tests.

In contrast to the present findings in mild to 
moderate $\mathrm{CHI}$ previous MRI study of patients representing a wider range of injury severity has revealed that the relation between depth of lesion and neurobehavioural functioning tends to strengthen over time. ${ }^{5}$ Wilson et al ${ }^{5}$ found that the relation between MRI findings and neuropsychological functioning in 25 adults with CHI of varying severity changed over time. Depth of lesion had a stronger relation to cognitive deficit at follow up (five to 18 months) than on the initial examination.

Our study also shows the heterogeneity of mild to moderate $\mathrm{CHI}$ in regard to the persistence of cerebral abnormality detected by MRI; notably 19 of 27 patients (70\%) studied at all three examinations still had evidence of an intracranial lesion one month after sustaining a mild to moderate head injury. At the same time, it should be acknowledged that four of the eight patients whose hyperintensities had resolved by one month still exhibited deficits in one or both domains of the neurobehavioural examination. Whether the pathophysiological basis of these sequelae of mild to moderate $\mathrm{CHI}$ could be shown by metabolic imaging awaits further research.

This paper was presented in part at the American Association for Neurological Surgeons meeting on April 24, 1991 in New Orleans, Louisiana. The research was supported by grant NS21889. We are indebted to Lori Bertolino for data management and to Melanie Meiselbach and Liz Zindler for word processing.

1 Bydder GM, Steiner RE, Young JR, et al. Clinical NMR imaging of the brain: 140 cases. $A F R$ 1982;139:215-36. 2 Gandy SE, Snow RB, Zimmerman RD, et al. Cranial nuclear magnetic resonance imaging in head trauma. Ann Neurol 1984;16:254-7.

3 Han JS, Kaufman B, Alfidi RJ, et al. Head trauma evaluated by magnetic resonance and computed tomography: a comparison. Radiology 1984;150:71-7.

4 Jenkins A, Teasdale G, Hadley MDM, et al. Brain lesions detected by magnetic resonance imaging in mild and detected by magnetic resonance imaging

5 Wilson JTL, Wiedman KD, Hadley DM, Condon B, Teasdale $G$. Early and late magnetic resonance imaging and neuropsychological outcome after head injury. $\mathscr{f}$ Neurol Neurosurg Psychiatry 1988;51:391-6.

6 Kelly AB, Zimmerman RD, Snow RB, et al. Head trauma comparison of MR and CT-experience in 100 patients. AFNR 1988;9:699-708.

7 Snow RB, Zimmerman RD, Gandy SE, et al. Comparison of magnetic resonance imaging and computed tomography in the evaluation of head injury. Neurosurgery 1986;18:45-52.

8 Levin HS, Amparo E, Eisenberg HM, et al. Magnetic resonance imaging and computerised tomography in relation to the neurobehavioral sequelae of mild and moderate head injuries. $¥$ Neurosurg 1987;66:706-13.

9 moderate head injuries. F Neurosurg 1987;66:706-13. consciousness. A practical scale. Lancet 1974;2:81-4.

10 Levin HS, Mattis S, Ruff RM, et al. Neurobehaviora outcome following minor head injury: a three-cente study. $\mathcal{F}$ Neurosurg 1987;66:234-43.

11 Rimel RW, Giordani B, Barth JT, et al. Disability caused by minor head injury. Neurosurgery 1981;9:221-8.

12 Rimel RW, Giordani B, Barth JT, et al. Moderate head injury: completing the clinical spectrum of brain trauma. Neurosurg 1982;11:344-51.

13 Levin HS, O'Donnell VM, Grossman RG. The Galveston orientation and amnesia test. A practical scale to asses cognition after head injury. $f$ Nerv Ment Dis 1979;167:675-84

14 Adams JH, Graham D, Scott G, Parker LS, Doyle D. Brain damage in fatal non-missile head injury. $f$ Clin Pathol damage in fatal no

15 Holbourn AHS. Mechanics of head injuries. Lancet 1943;2:438-41.

16 Nelson HE. A modified card sorting test sensitive to frontal lobe defects. Cortex 1976;12:313-24.

17 Benton AL. Differential effects in frontal lobe disease. Neuropsychologia 1968;6:53-60.

18 Benton AL, Hamsher K. Manual for the multilingual aphasia examination. Iowa City: University of Iowa, 1978

19 Jones-Gotman M, Milner B. Design fluency: the invention of nonsense drawings after focal cortical lesions. Neuropsychologia 1977;15:653-74.

20 Buschke $\mathrm{H}$, Fuld $\mathbf{P}$. Evaluating storage, retention, and retrieval in disordered memory and learning. Neurology 1974;24:1019-25.

21 Levin HS, Larrabee GJ. Disproportionate decline in visuospatial memory in human aging. Soc Neurosci Abstr 1983;9:918 (abstract)

22 Kimura D. Right temporal-lobe damage. Arch Neurol 1963;8:264-71. 